\title{
A Model Trend and Application of Niger Delta Ultrasonic Field Data to Manage Erosion Corrosion in Pipelines and Flowlines
}

\author{
Boniface A. Oriji and Azubuike H. Amadi
}

\begin{abstract}
Corrosion of pipelines and other industrial facilities has led to several hazards and catastrophic events in the petroleum industry. The corrosion of pipelines can occur in different ways, as materials tend to go back to original state. This work focused on the erosion corrosion of pipelines due to sand production. Several analysis following best practices introduced in this work where carried out on field inspection data on pipelines and flowlines in which a trend was identified. This trend generated models such as erosion trend angle (ETA) and erosion trend factor (ETF) which will be used for reviews, judgment and sensitivity analysis during corrosion management. The criterion for criticality of ETA was 30 degrees for the purpose of this work and recommended that users could vary to fit work objectives. Five test points where used to establish ETA and ETF values for major decision of criticality for erosion corrosion as shown in Table 2. To enhance the use of these models and known corrosion tools, a software application known as HAZUTREND was developed using python programming and machine learning algorithms for linear regression. An erosion corrosion management procedure was also introduced as a result of analysis made, to optimize decision making.
\end{abstract}

Index Terms-Erosion Corrosion, Erosion Trend Angle, Erosion Trend Factor, Hazutrend, Sand Production.

\section{INTRODUCTION}

About $75 \%$ to $85 \%$ of drill pipe loss is as a result of corrosion [5]. Corrosion affects production operation through sand production, localized stresses and chemical reactions during pressure and temperature changes. It also affects drilling operations through electrochemical process in the presence of electrolytes in drilling fluid. It affects completion equipment's using completion fluids as its electrolyte, especially deep sea, using its saline environment as its electrolyte. In General, the effect of corrosion on oil and gas facilities is greatly dependent on its environment.

Corrosion is an attack on a metal by electrochemical or chemical reaction within its environment, which result to a gradual reduction of the materials integrity and finally ending at failure in service. It is most times seen as nature's way of returning processed metal to its natural state.

According to Zoran, the damage caused by corrosion reaches about $4 \%$ to $5 \%$ of the national income of industrialized countries. Hence, specific funds were set aside

Published on November 27, 2019

B. A. Oriji is with the University of Portharcourt, Choba, PMB 5323 Nigeria (e-mail: aloriji2000@yahoo.com).

A. H. Amadi was with the Institute of Petroleum Studies, University of Portharcourt, Choba, PMB 5323 Nigeria (e-mail: azubuikehopeamadi@ gmail.com). for the mitigation of these problems [9].

The corrosion of metal surfaces as a result of velocity differences and erratic flow of fluids with or without particles over the metal surface resulting to the sweep away of any passivating film can be described as erosion corrosion. The accelerated loss of thickness is due to the mechanical effect of flow and a corrosive fluid medium. When the film has been wiped off, the material becomes vulnerable to the corrosion

Sand production which has been a major cause of erosion corrosion of pipelines has proved significant especially in areas of unconsolidated reservoirs such as Niger Delta. These effects on pipeline has brought about serval models and analogies on how to tackle pipeline losses and aid decision making of which this work introduced two models and programmed them as tools in a software (Hazutrend).

\section{LITERATURE REVIEW}

In Esan's research, areas of oil/water emulsion and continuous water phase where detected to predominantly corrode and the bottom location supports density effect due to gravity. The corrosion driver in the pipeline was also spotted after compositional studies on the fluids. However, the effects of erosion due to sand production were not considered as a possible cause of corrosion, especially at girth welds which also posed to contain defects [8].

Andrews has improved production due to treatment of sand topside as an alternative method for sand control while plugged intervals where cleaned up and flown back. However, in his work Pipeline integrity due high sand production was not taken into consideration and measures to checkmate safety issues which might result from leaks and other damages caused by increased sand production was not mitigated [7].

Clampon DSP monitor was used for erosion management by detecting sand produced at real time. Also, this instrument helped in the decision making of well potential in terms of sand produced. The study can be traced to erosion due to sand production but the effects on pipeline and other facilities was not captured, also the type of sand produce can have an influence on the rate of erosion on different wells [1].

The need for involving material and corrosion engineers in the design stage of carbon steel deep sea pipelines where clear and well stated in Wang's research. Also, Safety, Security, Health and Environment (SSH\&E) as used by Exxonmobil was taken into considerations in design., Wang and Haarseth's work, based on only carbon steel and the 
safety design towards the materials internal integrity will be mostly hindered by cost hike. However, the developed work will open up more literature to tackle this setback [6].

The Garon field was observed to produce sand which led to erosion of choke, screen, tubing, cut in flowline production, loss in man hour and production. Sand sensors where used here to identify sand produced but, the disparity observed between produced sand and the sand sensors where large, making managerial decision making hard [2].

The review of API RP 14E identified the inadequacy of API RP 14E to represent the combined effect of erosion and corrosion jointly. Also, the plethora of factors missed out in the API RP 14E model. Concrete solutions to enhance clarity of the API RP 14E equation was not provided in the review. However, the areas (phases present during erosion corrosion) where the use of the equation could pose treat to decision making was accounted for [4].

\section{Methodology}

\section{A. Data Gathering}

Ultrasonic thickness tester was used in the gathering of inspection data in pipelines and flowlines. The inspection data follows a regular pattern of measurement.

The pipeline dimeter was divided into four parts, following the clock quadrant numbers, which are 12, 03, 06 and 09. These points were considered based on the flow direction. Therefore, a precise point of inspection was followed for better corrosion monitoring.

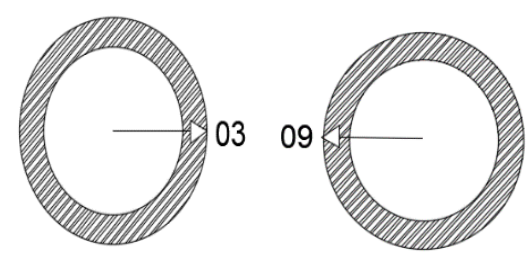

Fig. 1. NDT Test locations for bends under erosion corrosion
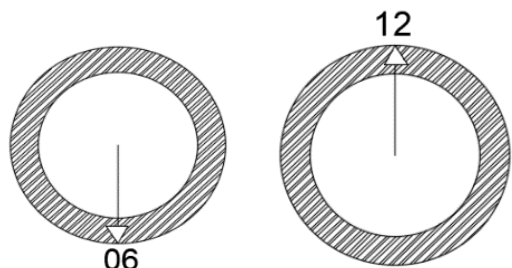

Fig. 2. NDT Test location for top-bottom pipe sections under erosion corrosion

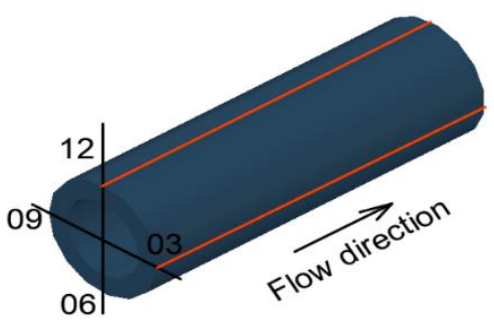

Fig. 3. Schematics of how test point depends on fluid direction

The major data obtained from this test was the thickness in $m m$ and time in years. Thickness was plotted against time and their slope was gotten from the trend in which the plot follows. From Pythagoras theory

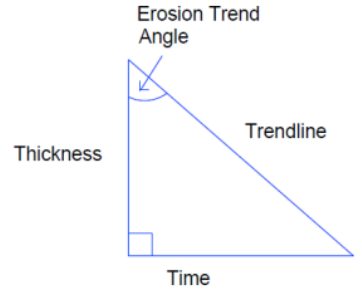

Recall:

$$
\mathrm{m}=\frac{\text { thickness change }}{\text { time change }}
$$

Also,

$$
\tan \theta=\frac{\text { opposite }}{\text { adjacent }}
$$

Therefore,

$$
\begin{aligned}
& \tan \theta_{\mathrm{e}}=\frac{1}{-\mathrm{m}} \\
& \theta_{\mathrm{e}}=\tan ^{-1}\left(-\mathrm{m}^{-1}\right)
\end{aligned}
$$

The negative sign makes up for the negative slope effect.

$$
\theta_{\mathrm{e}}=\text { erosion trend angle }
$$

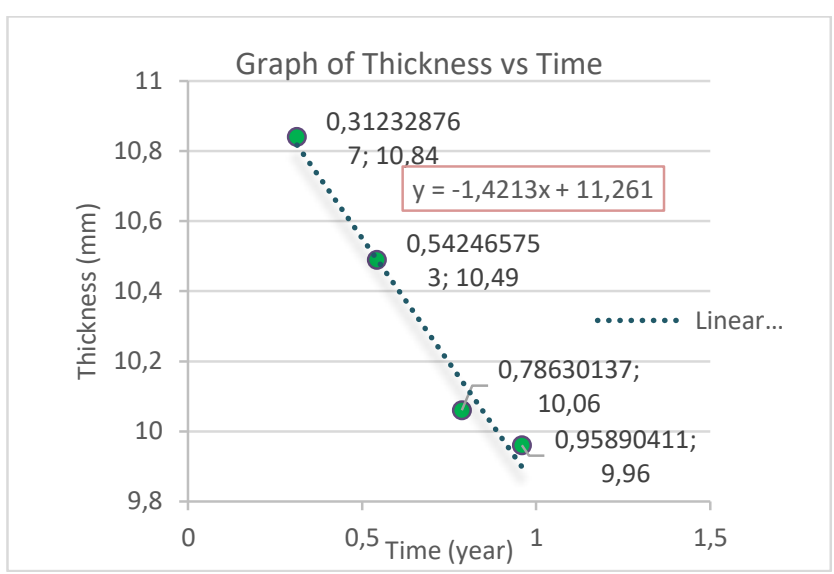

Fig. 4. Erosion trend plot from inspection data

From the trend in figure 4, a straight-line equation was generated corresponding to the equation below:

$$
\mathrm{y}=\mathrm{mx}+\mathrm{c}
$$

Generated equation:

$$
\mathrm{y}=-1.4213 \mathrm{x}+11.261
$$

From the generated "m"

$\theta_{\mathrm{e}}=\tan ^{-1}\left(-(-1.4213)^{-1}\right)$

$\theta_{\mathrm{e}}=35^{\circ}$

The Erosion trend factor $f_{e}$ was gotten from the ratio of the Erosion trend angle $\theta_{\mathrm{e}}$ to that of the maximum trend angle $\theta_{\mathrm{e}, \mathrm{max}}$ for a non-corroding material. 
The Maximum Trend angle $\theta_{\mathrm{e}, \max }$ is $90^{\circ}$

$$
\mathrm{f}_{\mathrm{e}}=\frac{\theta_{\mathrm{e}}}{\theta_{\mathrm{e}, \max }}=0.3889
$$

For the purpose of this work the Erosion Trend angle $\theta_{\mathrm{e}}<30^{\circ}$ was Critical. While, Erosion Trend angle $\theta_{\mathrm{e}}>$ $30^{\circ}$ was Not Critical

Also, Erosion Trend factor ranges from $0<f_{e} \leq 1$

The number "1" showed that the material has not corroded. While, the number " 0 " implied complete corrosion or lost pipe.

\section{B. Software Application}

Data gathered during inspection were easily analyzed using software applications. The model for erosion trend (ETA and ETF) and erosion rate was programmed into a software application using Machine Learning and Python programming language. The software developed in this work is known as HAZUTREND. It was built for the purpose of analyzing all corrosion related problems, but for the purpose of this work the packages present are:

1. The Erosion Trend Angle

2. Erosion Trend Factor

3. Erosion Rate

4. Decision making (Quick Managerial Decision box)

\section{1) Step One:}

The input data in the software are:

1. Inspection Thickness

2. Inspection Time

The time of inspection was inputted in years. That is, 2nd of February will be represented as the fraction $\frac{33 \text { days }}{365 \text { days }}=$ 0.09 years

While, thickness was in millimeters $(\mathrm{mm})$.

\section{2) Step Two:}

The plot button generated the erosion trend angle alongside all calculations dependent on the trend such as the Erosion Trend Angle and Erosion Trend Factor.

The calculation of the erosion rate was also initiated at the click of the plot button.

\section{3) Step Three:}

The decision box presented the best suggestion from analysis made from the model and trend. These decisions help to guide the corrosion engineer on what to do about the present integrity of the pipeline.

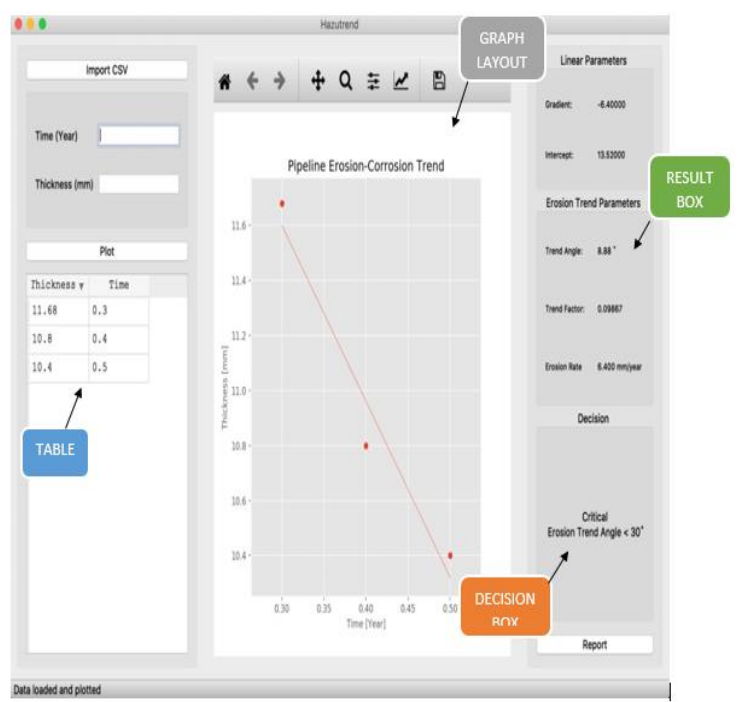

Fig. 5. Erosion Analysis confirming the validity of the Model and Software (HAZUTREND)

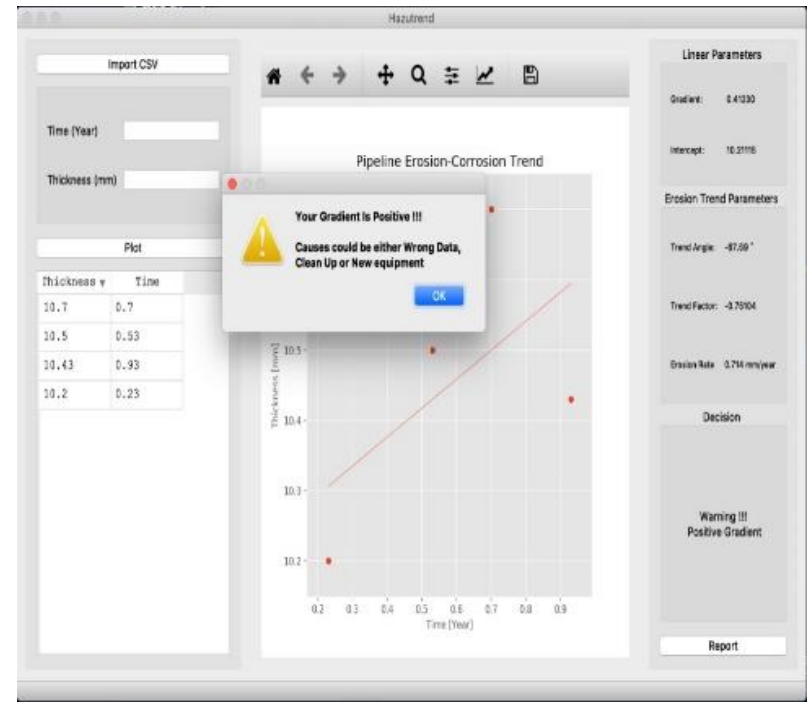

Fig. 6. Software Error Representation during wrong input data

TABLE I: INSPECTION TEST RESUlt ON FLOWLINES IN NIGER DELTA FIELD IN 2017

\begin{tabular}{cccccccc}
\hline \hline $\begin{array}{c}\text { Test Point 1 } \\
(\mathbf{S} / \mathbf{0 6})\end{array}$ & \multicolumn{2}{c}{$\begin{array}{c}\text { Test Point 2 } \\
(\mathbf{S} / \mathbf{0 9})\end{array}$} & \multicolumn{2}{c}{$\begin{array}{c}\text { Test Point 3 } \\
(\mathbf{S} / \mathbf{1 2})\end{array}$} & \multicolumn{2}{c}{$\begin{array}{c}\text { Test Point 4 } \\
(\mathbf{S} / \mathbf{0 9})\end{array}$} \\
\hline $\begin{array}{c}\mathrm{Th} \\
(\mathrm{mm})\end{array}$ & $\begin{array}{c}\mathrm{T} \\
(\mathrm{yr})\end{array}$ & $\begin{array}{c}\mathrm{Th} \\
(\mathrm{mm})\end{array}$ & $\begin{array}{c}\mathrm{T} \\
(\mathrm{yr})\end{array}$ & $\begin{array}{c}\mathrm{Th} \\
(\mathrm{mm})\end{array}$ & $\begin{array}{c}\mathrm{T} \\
(\mathrm{yr})\end{array}$ & $\begin{array}{c}\text { Th } \\
(\mathrm{mm})\end{array}$ & $\mathrm{T}(\mathrm{yr})$ \\
\hline 11.57 & 0.31 & 11.49 & 0.31 & 1142 & 0.31 & 11.68 & 0.31 \\
\hline 11.22 & 0.54 & 11.28 & 0.54 & 10.84 & 0.54 & 10.8 & 0.54 \\
\hline 11.22 & 0.78 & 11.27 & 0.78 & 10.84 & 0.78 & 10.4 & 0.78 \\
\hline \hline
\end{tabular}

TABLE II: RESULT FROM SOFTWARE APPLICATION

\begin{tabular}{llll}
\hline \hline & ETA & ETF & Decision \\
\hline Test Point 1 & $53.93^{\circ}$ & 0.599 & Not Critical \\
\hline Test Point 2 & $65.38^{\circ}$ & 0.726 & Not Critical \\
\hline Test Point 3 & $39.64^{\circ}$ & 0.440 & Not Critical (Monitor) \\
\hline Test Point 4 & $8.62^{\circ}$ & 0.096 & Critical \\
\hline \hline
\end{tabular}




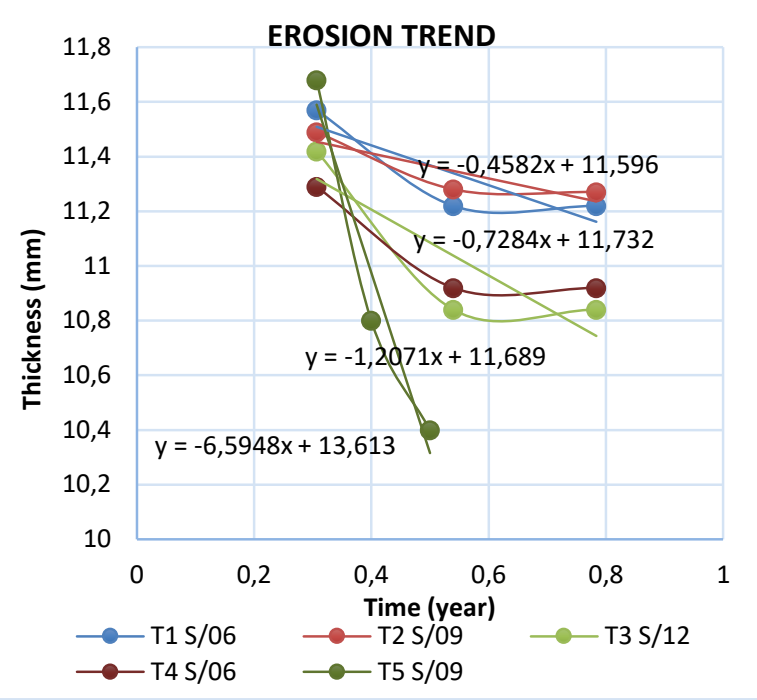

Fig. 7. Erosion Tend Plot of Inspection data

\section{Model Limitations}

Deposits and Clean up: During production, deposits in pipelines (wax, hydrate or sediments) could cause a variation in data collection while inspecting pipelines. A typical example was during ultrasonic thickness testing of a pipe attacked by wax. The thickness detected, since it was done from the outer part of the pipe was larger than the actual pipe thickness. Hence, when there was a clean-up (during pigging or mechanical scraping) and an inspection was repeated on the same pipeline, the thickness value reduced.

Wrong Input Data: The causes of incorrect data imputation could be numerous, some of which are, wrong unit conversion, poor physical or mental state of inspector, faulty Instruments, etc.

Replacement of Pipeline: Pipelines may be replaced with new ones after being in service for a long time. The reason for replacement might be due to erosion corrosion of previous pipe. This replacement was taken into account on the software to avoid a negative plot. Hence, inspection restarts on replacement of pipes.

\section{DISCUSSION AND FINDINGS}

Inspections of pipelines were done at intervals. Consistency and technicalities during inspection contributes to the quality of data acquired. A typical example is the use of the clock quadrant numbers 12, 03, 06 and 09 on pipelines as points of inspection. The sides 03 and 06 were observed to corrode more at bend because of the sharp contact of both fluids and sand with the walls of the pipe, while the point 06 experienced erosion and localized corrosion (pitting) due to water settling (density effect).

The trends observed during this research work have been validated to be consistent. This implies that erosion corrosion gradually increases thickness loss with time. The erosion trend factor, as a tool for measuring the severity of pipeline erosion can be used in pipeline integrity calculations at the design stage as a safety factor for known or analog service conditions.

According to Daleel the Direct gross average operating

cost for pipeline laying vessels is estimated to be within $\$ 150,000$ to $\$ 350,000$ per day which depends on the size, equipment's setup and age [3].

If we assume $\$ 200,000$ per day to be the cost of laying and the workover job on a pipeline attacked by erosion corrosion which was not managed properly or detected on time was to last for 3 days.

Cost of workover job $=\$ 200,000 \times 3=\$ 600,000$

If this was a production line, producing at $200,000 \mathrm{bbls}$ per day and the oil price is at $\$ 65$.

Daily production cost of 200,000 bbls $\times \$ 65=\$ 13,000,000$ will be lost for 3days, making it sum up to $\$ 13,000,000 \times 3$ days $=\$ 39,000,000+\$ 600,000=\$ 39,600,000$

A total of $\$ 39,600,000$ is lost due to late decision

making or inability to manage erosion corrosion.

With the Hazutrend Corrosion Inspector software, the corrosion trends considered critical can be identified and repair time can be minimized to a maximum of 1day, which could cost $\$ 13,200,000$ as compared to $\$ 39,600,000$ or more. Using this scenario, the company will be able to save $\$ 26,400,000$.

Chart of Economic benefit of Software Model

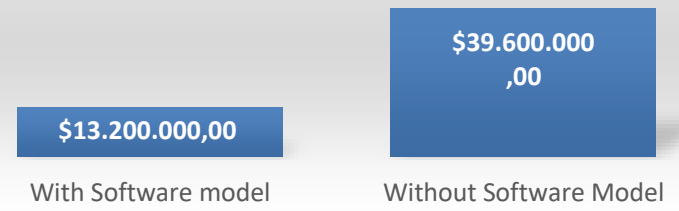

Fig. 8. Comparison of OPEX with and without software

CALIBRATION OF EQUIPMENT

nspection tools should be calibrated frequently for quality assurance purpose)

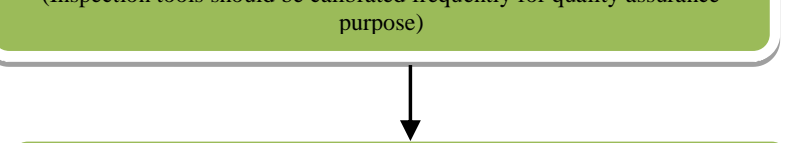

WORK PERMIT

(Also known as Permit to Work "PTW", it is necessary to confirm safety of working site before inspection

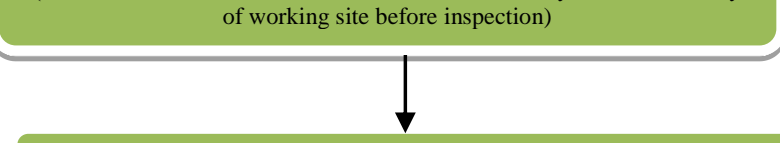

INSPECTION

(This is done at site using certified tools)

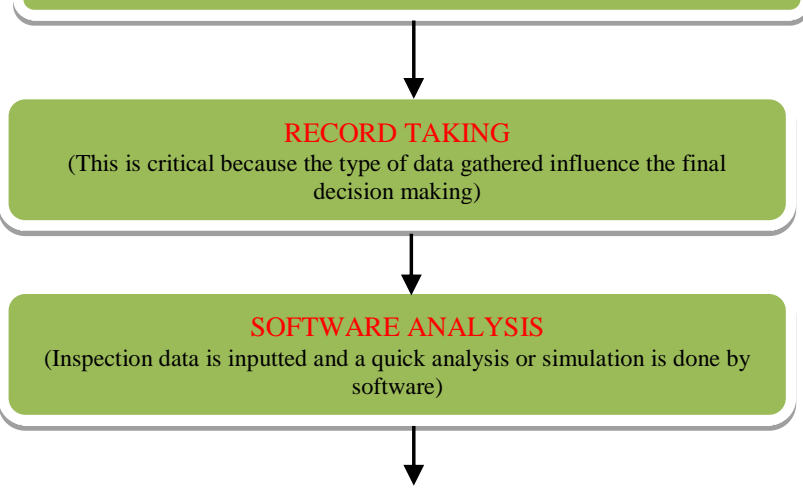

MANAGEMENT DECISION

(Software analysis and human intelligence guides the management on final decision making, this might be to choke down, change flowline, maintenance, etc.)

Fig. 9. Erosion Management Flow Chart 


\section{CONCLUSION}

This study, after examination of several erosion inspection data was able to identify methods of data

collection in line with best practices that will simplify and help in accuracy of erosion analysis. The five test points which showed ETA's of $53.93^{\circ}, 65.53^{\circ}, 39.64^{\circ}, 52.40^{\circ}$ and $8.62^{\circ}$ helped identify areas of severity. The trends observed led to conclusions highlighting the fact that erosion trend factor and erosion trend angle are efficient tools in decision making, reviews, judgments and sensitivity analysis of a sand producing well, or an erosion corrosion attacked facility. A simplified erosion management flowchart was derived from the analysis carried out to help as procedures in industrial use. The economic importance of this software is key, since the study proved the possible benefits of cost saved as a result of the use of the HAZUTREND software. The user, which could be a company, individual, or institute can set its own parameters for criticality of erosion corrosion which proves that the software application is user friendly and flexible in service. For the purpose of this work an Erosion trend angle less than $30^{\circ}$ is considered critical, while above $30^{\circ}$ is not critical.

Industrial hazards caused by eroding pipelines and flowline and be drastically minimized with the use of this model and software application.

\section{RECOMMENDATION}

This work has been built from the basic principles from literature on erosion corrosion of onshore and offshore pipelines. Therefore, it is recommended that pilot projects improve on the effectiveness of this model and introduce more packages in the HAZUTREND version 0.1.1 for a better erosion corrosion management. The erosion trend factor can be used to analyze the level of severity of a particular type of pipe (e.g. carbon steel) to erosion corrosion, it is recommended that after understanding a materials performance over a time, this can then be factored into the design of facilities using such materials. This software can be used in companies, institutions and for individual works on erosion corrosion.

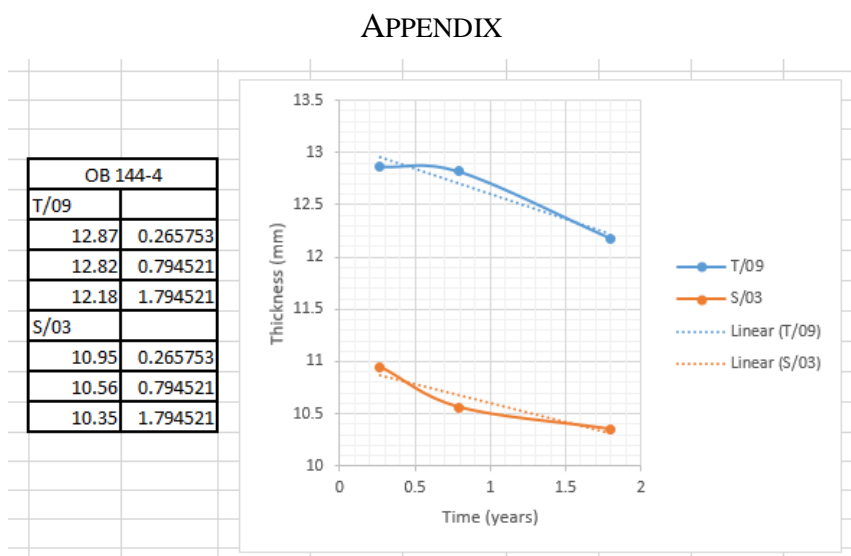

Fig. 9. Erosion Trend on OB 144-4 Flowlines

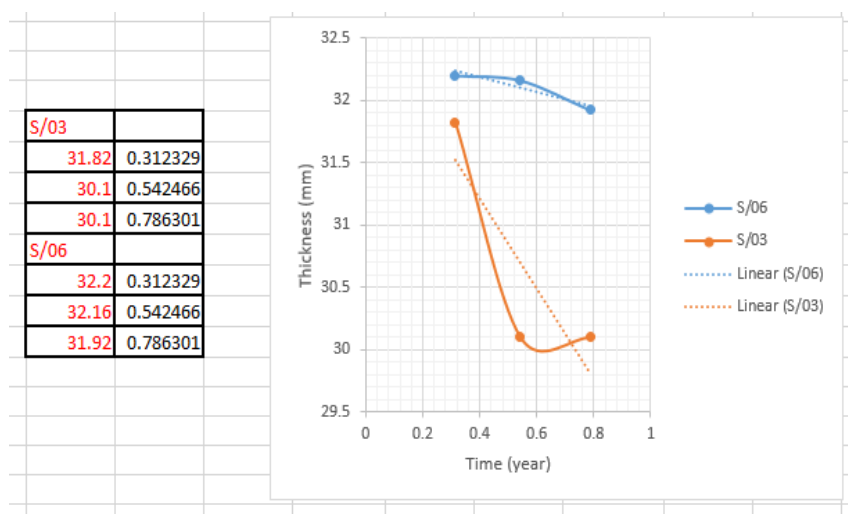

Fig. 10. Erosion Trend on OB 60-4 Flowlines

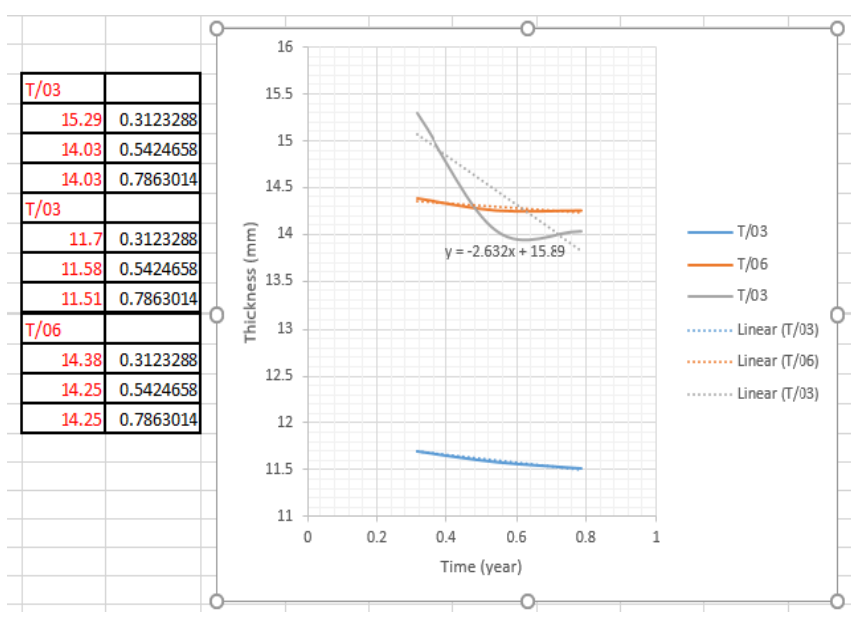

Fig. 11. Erosion Trend on OB 114-4 Flowlines

\section{ACKNOWLEDGMENT}

The Institute of Petroleum Studies is fundamental in the success of this work through the knowledge, exposure and enabling environment created during the course of this work. A. H. Amadi specially thanks Mr and Mrs Rowland Amadi for moral support and assistance during this research.

\section{REFERENCES}

[1] Bibobra Ikporo, Okotie Sylvester and Ichenwo John-Lander (2014) Minimizing the risk of erosion damage of some wells in Niger Delta field with Clampon DSP monitor, The International Journal of Engineering, Vol. 2, 121-127, ISSN: 5675-0715

[2] Bibobra Ikporo and Okotie Sylvester (2015). Effect of Sand invasion on Oil Well Production: A Case study of Garon Field in the Niger Delta, The International Journal of Engineering and Science, Vol. 4 , 64-72, ISSN: $2319-1813$

[3] Daleel (2015). Pipe Laying Vessels. Retrieved from https://www.scmdaleel.com/category/pipe-laying-vessels/57

[4] Fazlollah Madani Sani, Khlefa Esakul and Sytze Huizinga (2019). Review of API RP 14E erosion velocity equation: Origin, applications, misuses and limittions. NACE 2019 Conference: Corrosion. Paper No: 13206. Nashville TN Retrieved from https://www.researchgate.net/publication/332160517_Review_of_the _API_RP_14E_erosional_velocity_equation_origin_applications_mis uses_and_limitations

[5] Godwin A. C. (2019). PPD 808-3: Well control; Drill pipe corrosion [Power point slides]

[6] Hongbin Wang and Cecilie A. Haarseth (2014). Deepwater Flowline Internal Corrosion Control - Safety by Design. International Ocean and Polar Engineering Conference, Busan. 394 - 401, ISBN 978-1 880653 91-3

[7] J. Andrews, H. Kjørholt and H. Jøranson (2005). Production enhancement from sand management philosophy, SPE Journal, 2-3, 94511 
[8] Tope Esan, S. D. Kapusta and M. J. J. Simon Thomas (2001) Extreme Corrosion of a 20" Oil Pipeline in the Niger Delta region, NACE International, Paper No: 01629

[9] Zoran C. Petrović (2016). Catastrophes caused by corrosion. Vojnotehicki Glasnik/Military Technical Courier, 64, 1048-1064, DOI: $10.5937 /$ vojtehg64-10388

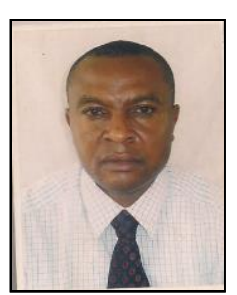

Boniface A. Oriji is a Petroleum Engineer of International repute who had his (B.ENG), (M.ENG) and (Ph.D) in Petroleum \& Gas Engineering, from the University of Port Harcourt, Rivers State , Nigeria.

He has twenty (20) years working experience in the oil \& Gas industry as an international staff who worked in Nigeria, United States, United Kingdom, South Africa, Gabon, Cameroon, Congo, France, Angola, Egypt, Oman, Abu Dhabi and Tanzania with Halliburton Overseas. He was a Senior Technical Professional in charge of training for Sub-Sahara and Central Africa before his retirement to academics. He is presently a Senior Lecturer in the Department of Petroleum \& Gas Engineering, University of Port-Harcourt and a Consultant to Oil and Gas Industries. He is also the Assistant Director of the Institute of Petroleum Studies UNIPORT and a subject expert in Drilling and Completion Engineering. He has published widely and given numerous presentations and training both locally and internationally in the area of his expertise.

Engr. Dr. Oriji is a member of the Society of Petroleum Engineers (SPE), Nigerian Society of Engineer (NSE) and a Registered Professional
Petroleum Engineer with the Council for the Regulation of Engineers in Nigeria (COREN).

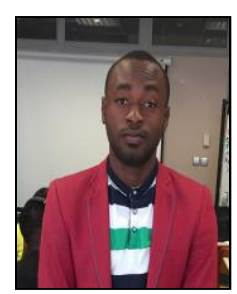

Azubuike H. Amadi was born on the 4th of March 1995 in Rivers State, Nigeria. He has a B. Eng. in Materials and Metallurgical Engineering form the Federal University of Technology, Owerri and MSc. in Petroleum Engineer and Project Development from the Institute of Petroleum Studies UNIPORT/IFP School, Choba, Port Harcourt, Rivers State, Nigeria.

$\mathrm{He}$ has working experience in the oil \& Gas Industry, FMGC and Construction/Fabrication, and gained soft skills in HYSYS, SEPAL, Pipesim, Prosper, Perform, Eclipse, Sapphire, Autocad, Ansys, Excel VBA and Python Programming.

Mr Amadi is an active member of the National Association of Materials and Metallurgical Engineering Students (NAMMES), Society of Petroleum Engineers (SPE) and Nigerian Society of Engineers (NSE). He has received the following awards; TEPNG/NNPC Joint Venture Postgraduate Scholarship Scheme, NYSC Certificate of Commendation for Humanitarian service, Ardo-kola Local Government Council, Taraba State commendation for Service, FUTO SUG Certificate of Service as Judge of FUTO by Prof. C. C. Asiabaka (Vice Chancellor), ST. Marks Anglican Church Eziobodo, Certificate of Honour, National Union of Rivers State Students (NURSS) Certificate of Service and National Association of Materials \& Metallurgical Engineering Student Certificate of Service by Dr. C. S Nwobodo (Head of Department). 